Original Article

\title{
SIMULTANEOUS ESTIMATION OF MOMETASONE FUROATE AND FORMOTEROL FUMARATE BY HPLC METHOD IN ROTACAPS
}

\section{AARTI S. ZANWAR* , DHANYA B. SEN, ASHIM KUMAR SEN, A. K. SETH}

Department of Pharmacy, Sumandeep Vidyapeeth University, Piparia, Waghodia, Vadodara 391760, Gujarat, India Email: aarti.zanwar@gmail.com

Received: 16 Jan 2018 Revised and Accepted: 20 Dec 2018

\section{ABSTRACT}

Objective: To develop and validate a simple and sensitive RP-HPLC method for the simultaneous determination of mometasone furoate (MOM) and formoterol fumarate (FOR) in pharmaceutical dosage forms.

Methods: In RP-HPLC method, chromatographic separation was achieved using a mixture of a solvent system consisting of methanol-water (pH 3.5 ) in the ratio of $85: 15 \% \mathrm{v} / \mathrm{v}$ at a flow rate of $1 \mathrm{ml} / \mathrm{min}$ and detection was carried out at $225 \mathrm{~nm}$.

Results: The run time for the simultaneous estimation of drugs for the proposed method was $10 \mathrm{~min}$ as drugs eluted at $5.217 \mathrm{~min}$ (MOM) and 8.650 min (FOR). The linearity was found in the range of 33.33-299.97 $\mu \mathrm{g} / \mathrm{ml}$ and $1-9 \mu \mathrm{g} / \mathrm{ml}$ for MOM and FOR, respectively. The values of limit of detection and limit of quantification were $3.634,0.266 \mu \mathrm{g} / \mathrm{ml}$ and $11.014,0.807 \mu \mathrm{g} / \mathrm{ml}$, which indicates the sensitivity of the method for the estimation of MOM and FOR, respectively. The results of recovery studies for both the drugs were within the range i.e. 98.87-101.48 \% which indicates the accuracy of the method. Relative standard deviation obtained from repeatability and reproducibility studies were less than $2 \%$ indicates the precision of the method. The proposed method was validated according to ICH guidelines.

Conclusion: The proposed RP-HPLC method was found to be sensitive and precise because of the low LOD, LOQ and \% RSD values $(<2)$. The proposed work does not require acetonitrile and ion pairing reagent as compared to the reported methods. Therefore, method can be used preferably for routine analysis due to its simplicity and economic advantages.

Keywords: RP-HPLC, Mometasone furoate, Formoterol fumarate, Analytical method

(C) 2019 The Authors. Published by Innovare Academic Sciences Pvt Ltd. This is an open access article under the CC BY license (http://creativecommons.org/licenses/by/4.0/) DOI: http://dx.doi.org/10.22159/ijpps.2019v11i2.24799

\section{INTRODUCTION}

Management of asthma is improved by combining inhaled corticosteroids with long-acting $\beta_{2}$-agonists. Inhalation permits effective delivery of the drugs in high concentration to target sites within the lung, minimizing systemic exposure [1]. Combinational therapy of mometasone furoate (MOM) and formoterol fumarate (FOR) has been used in the treatment of COPD and asthma as it produces the additive effects for improving the symptoms, lung functions and reduces exacerbation in patient [2]. MOM (fig. 1) is a white crystalline powder, soluble in acetone, dichloromethane and slightly soluble in ethanol and a highly potent synthetic chlorinated glucocorticosteriod [3]. FOR (fig. 2) is a white crystalline, soluble in ethanol and methanol, slightly soluble in water, practically insoluble in acetonitrile. It appears to be more effective than shorter acting $\beta_{2}$ agoinst in the treatment of nocturnal and exercise induced asthma. Moreover, it acts locally in the lung as a bronchodilator [4].

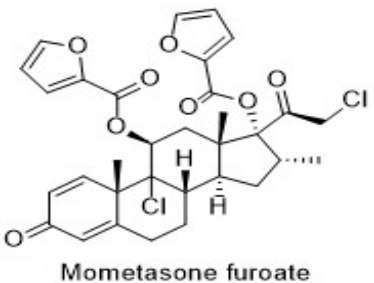

Fig.1: Chemical structure o mometasone furoate

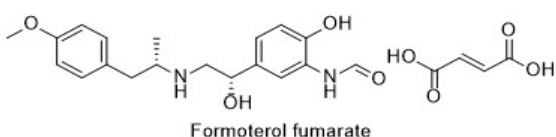

Fig. 2: Chemical structure of FOR formoterol fumarate
The literature survey reveals that several analytical methods have been published for the estimation of MOM alone and in combination with other drugs like fusidic acid [5], oxymetazoline [6] terbinafine $\mathrm{HCl}$, nadifloxacin [7], eberconazole nitrate [8], miconazole, hydrocortisone [9], ketoconazole [10], salicylic acid [12] etc. Some of these methods include HPLC, GC, supercritical fluid chromatography and UV spectrophotometry. Various methods have also been reported for the estimation of FOR alone [13] and in combination with other drugs like budesonide $[14,16]$, tiotropium bromide $[15]$ including HPLC, GC, and UV spectrophotometry [13-17]. A spectrophotometric and HPLC method for the simultaneous determination of MOM with FOR has also been reported in meter dose dosage form [17-19]. In one of the reported method, the mobile phase contained ion pairing reagents which will decrease the column life and was less sensitive. In the second method use of $60 \%$ ACN may increase the cost of analysis. The present study proposes a new RP-HPLC method using a mixture of methanol and water as a mobile phase for simultaneous estimation for MOM and FOR in rotacaps with the run time of $10 \mathrm{~min}$.

\section{MATERIALS AND METHODS}

\section{Instrumentation}

Younglin (S. K) gradient HPLC system combined with UV detector and Software-Autochro-3000 was used. Toshcon Ultrasonic Cleaner (Sonicator) of model SW 4 was used for sonication purpose. Digital Balance of Model Adventurer Pro AVG 264C (0.0001 gm to $260 \mathrm{gm}$ ) was used for weighing purpose. Digital pH meter of Model: S901was used for $\mathrm{pH}$ measurement.

\section{Chemicals and reagents}

Standard drugs of MOM and FOR were obtained as gift samples from Sun Pharmaceutical Industries Ltd., Vadodara (Gujarat) India. The marketed formulation (Evocort ${ }^{\circledR}$, Cipla Ltd.) of rotacaps containing MOM $(200 \mu \mathrm{g})$ and FOR $(6 \mu \mathrm{g})$ was purchased from local market. All the chemicals and reagents used were of HPLC/analytical grade. 


\section{Chromatographic conditions}

The separation and quantitation of MOM and FOR were made on a $250 \mathrm{~mm} \times 4.6 \mathrm{~mm}$ (i.d.) thermo ( $5 \mu \mathrm{m}$ particle size) reversed phase $\mathrm{C}_{18}$ analytical column. The mobile phase was prepared by mixing methanol-water (pH 3.5 with $0.05 \%$ orthophosphoric acid) in the ratio of $85: 15 \% \mathrm{v} / \mathrm{v}$. The flow rate was set at $1 \mathrm{ml} \mathrm{min}^{-1}$. All detection was carried out at ambient temperature. The injection volume was $20 \mu \mathrm{l}$. The detector was set at $225 \mathrm{~nm}$ wavelength. Data acquisition was performed by Autochro-3000 software.

\section{Preparation of standard solution}

MOM (333 mg) and FOR (10 mg) were weighed accurately and transferred to a $100 \mathrm{ml}$ volumetric flask containing $25 \mathrm{ml}$ methanol and sonicated. It was further diluted up to the mark with methanol to get $3330 \mu \mathrm{g} / \mathrm{ml}$ of MOM and $100 \mu \mathrm{g} / \mathrm{ml}$ of FOR, respectively and labelled as a standard stock solution. Further dilution was made to get required concentration.

\section{Analysis of sample formulation}

The powder content of twenty rotacaps (Each Rotacap contain FOR: $6 \mu \mathrm{g}$; MOM: $200 \mu \mathrm{g}$ ) was accurately weighed. A portion of powder (403.83 mg) equivalent to $0.1 \mathrm{mg}$ of FOR and $3.33 \mathrm{mg}$ of MOM was transferred to a $10 \mathrm{ml}$ volumetric flask containing $5 \mathrm{ml}$ methanol. The solution was sonicated for $15 \mathrm{~min}$ and made up to mark with methanol and filtered through $0.45 \mu \mathrm{m}$ membrane filter. Further suitable aliquots of above sample formulation were diluted using mobile phase to obtain the concentration of both the drugs within the linearity range. The solutions were injected and chromatograms were recorded by the proposed RP-HPLC method. Based on the peak area of analytes, percentage assay of the formulation was calculated.

\section{Method validation}

The developed method for the simultaneous determination of MOM and FOR was validated for specificity, linearity, precision, accuracy, sensitivity, robustness and system suitability according to the International Conference on Harmonization guidelines [20].

\section{Specificity}

The selectivity of the RP HPLC method was checked by comparison of the chromatograms obtained from the samples and the corresponding placebo. The resolution factor between the MOM and FOR was 11.63 indicating that the method remained selective for both the drugs under test conditions.

\section{Linearity and range}

Linearity was evaluated by linear regression analysis. The linearity of the method was studied by analyzing different aliquots of binary mixture of standard solutions in the range of 33.33-299.97 $\mu \mathrm{g} / \mathrm{ml}$ and $1-9 \mu \mathrm{g} / \mathrm{ml}$ for MOM and FOR, respectively in five replicates. Calibration graphs were plotted using peak areas versus concentration. The results were subjected to regression analysis by the least squares method to calculate the values of slope, intercept and correlation coefficient.

\section{Precision}

It was studied by carrying out repeatability, intraday and interday precision. Repeatability study was evaluated by analyzing the solution ( $99.99 \mu \mathrm{g} / \mathrm{ml}$ and $3 \mu \mathrm{g} / \mathrm{ml}$ of MOM and FOR) six times in HPLC system and \% RSD was calculated. Intraday and interday precision was carried out by analyzing three replicate injections of MOM at different concentration 99.99, 166.65, $233.31 \mu \mathrm{g} / \mathrm{ml}$ and FOR $3,5,7 \mu \mathrm{g} / \mathrm{ml}$ on the same day and different day which was expressed in term of \% RSD.

\section{Accuracy}

Recovery studies were carried out by the addition of standard drug to pre-analyzed sample solution (FOR: $3 \mu \mathrm{g} / \mathrm{ml}$; MOM: $99.9 \mu \mathrm{g} / \mathrm{ml}$ ) at three different levels: 50, 100 and $150 \%$ to validate the accuracy parameter. The result of the accuracy study was assessed based on the percentage of standard FOR and MOM recovered from the formulation using following formula.

$\%$ Recovery $=$ (Amount of drug found after addition of standard drug-Amount of drug found before addition of standard drug)/(Amount of standard drug added) x 100

(Amount of drug found after addition of standard drug $\%$ Recovery $=\frac{- \text { Amount of drug found before addition of standard drug) }}{\text { (Amount of standard drug added) }} \times 100$

\section{Sensitivity}

Sensitivity was evaluated by calculating the limit of detection and limit of quantification of FOR and MOM using the following equation as per ICH guidelines.

LOD $=3.3 \times \sigma / S$

$\mathrm{LOQ}=10 \times \sigma / S$

Where, $\sigma=$ Standard deviation of the response,

$\mathrm{S}=$ Slope of the calibration curve.

\section{Robustness}

Robustness was checked based on slight alteration in some critical parameters to allow routine laboratory use. It was performed by making slight alteration in proportion of methanol in mobile phase $(85 \pm 2 \% \mathrm{v} / \mathrm{v})$, flow rate $(1 \pm 0.1 \mathrm{ml} / \mathrm{min})$ and buffer $\mathrm{pH}(3.5 \pm 0.2$ units). The solutions were analysed, values of peak area and retention time were recorded.

\section{System suitability}

System suitability tests were performed to confirm that the instrument was in appropriate condition for the analysis to be performed. Six replicates of the standard solution was injected and chromatograms were recorded to confirm the suitability of the chromatograph. Peak area reproducibility, number of theoretical plates, resolution and tailing factor were recorded.

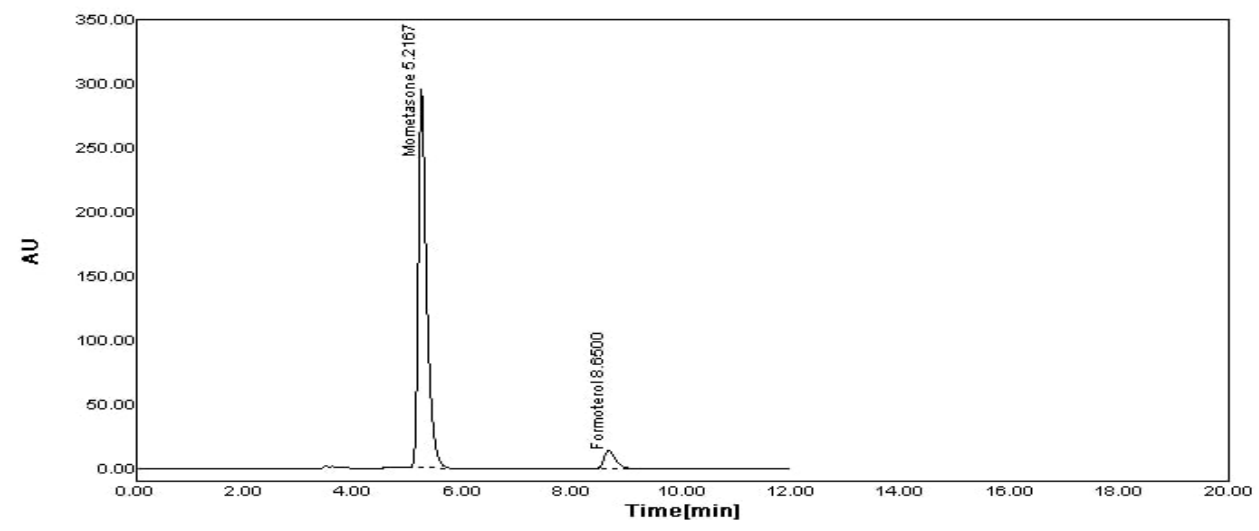

Fig. 3: HPLC chromatogram of MOM and FOR under optimised condition 


\section{RESULTS}

For developing well suited RP-HPLC method for analysis, parameters like detection wavelength, mobile phase composition, optimum $\mathrm{pH}$ and concentrations of the standard solution were comprehensively studied. The working standard solution was scanned in the range of 190-400 nm. At $220 \mathrm{~nm}$, both the drugs gave satisfactory absorbance with due consideration in difference of their concentration and absorbance intensity. Several trials were carried out with different ratios of methanol and water for optimization of the mobile phase. Water: methanol in the ratio of 15:85 \% v/v gave good resolved peaks, but tailing was observed in FOR peak. Numerous trials of mobile phase in the $\mathrm{pH}$ range of 3-5 were also tried. A solvent system of methanolwater (pH adjusted to 3.5 with $0.05 \%$ ortho phosphoric acid) in the ratio of $(85: 15 \% \mathrm{v} / \mathrm{v})$ gave optimum peaks with a flow rate of 1.0 $\mathrm{ml} / \mathrm{min}$. MOM [retention time $\left(\mathrm{t}_{\mathrm{R}}\right) 5.217 \mathrm{~min}$ ] was eluted first followed by FOR [retention time $\left(t_{R}\right) 8.650 \mathrm{~min}$ ] as shown in fig. 2 .

\section{Validation of the developed method}

The developed method was validated as per ICH guidelines. The specificity analysis revealed the HPLC method did not suffer any interferences from the formulation excipients, because no other peaks were observed at the retention times of MOM and FOR.

The linearity range was optimized by analyzing the solution of MOM and FOR at different concentration range. The calibration curve was constructed by plotting concentration of standard solution against mean peak area and the regression equation was computed. The goodness of fit $\left(R^{2}\right)$ was found to be 0.9997 for both the drugs, indicating a linear relationship between the concentration of analyte and peak area, as shown in table 1 . The LOD and LOQ values were, $3.634,11.014 \mu \mathrm{g} / \mathrm{ml}$ and $0.266,0.807 \mu \mathrm{g} / \mathrm{ml}$, respectively for MOM and FOR which indicates the sensitivity of the method.

The intra-day and inter-day reproducibility values, expressed as percent relative standard deviation were less than 2 and percent relative standard deviation of repeatability study was less than 1 , which ensures the reliability of results as shown in table 1.

Accuracy was determined by comparing the amount found (concentration) with the amount added (concentration). The mean percentage recoveries were calculated for MOM and FOR. The results are shown in table 2 which indicates that there was no interference from the excipients. All parameters described under robustness studies were analysed, but no significant changes were found in retention time, peak area and symmetry of the peaks as mentioned in table 3. It was found that the values of system suitability parameters were within the acceptable limits as recommended in ICH guidelines (table 4).

The amount found in percentage which were close to 100 and relatively low \% RSD values shows that the developed method was successfully applied to analyze MOM and FOR in rota caps (table 5).

Table 1: Results of linearity and precision studies of proposed method

\begin{tabular}{lll}
\hline Parameters & MOM & FOR \\
\hline Linearity range $(\mu \mathrm{g} / \mathrm{ml})$ & $33.33-299.97$ & $1-9$ \\
Correlation coefficient & 0.9997 & 0.9991 \\
Regression Equation & & 51.351 \\
Slope & 18.922 & 6.533 \\
Intercept & -24.204 & 0.266 \\
LOD $(\mu \mathrm{g} / \mathrm{ml})$ & 3.634 & 0.807 \\
LOQ $(\mu \mathrm{g} / \mathrm{ml})$ & 11.014 & 0.827 \\
Precision $(\% \mathrm{RSD}){ }^{*}$ & & 1.211 \\
Repeatability of measurement $(\mathrm{n}=6)$ & 0.751 & 1.700 \\
Intra-day (n=3) & 1.207 & \\
Inter-day (n=3) & 1.605 & \\
\hline
\end{tabular}

${ }^{*} \mathrm{n}=$ number of determinations, \% RSD (Percentage relative standard deviation).

Table 2: Results of recovery studies of proposed method

\begin{tabular}{lllll}
\hline Level (\%) & MOM & & FOR & RSD (\%) \\
\cline { 2 - 5 } & Recovery (\%) & RSD (\%) & Recovery (\%) * & 1.830 \\
\hline 50 & $100.925 \pm 0.756$ & 0.749 & $99.053 \pm 1.813$ & 1.723 \\
100 & $101.482 \pm 0.696$ & 0.685 & $98.867 \pm 1.704$ & 1.692 \\
\hline
\end{tabular}

$*_{\text {mean }} \pm \mathrm{SD}(\mathrm{n}=3), \mathrm{SD}$ (Standard deviation), \% RSD (Percentage relative standard deviation)

Table 3: Results of robustness studies of the proposed method

\begin{tabular}{|c|c|c|c|c|c|}
\hline \multirow[t]{2}{*}{ S. No. } & \multirow[t]{2}{*}{ Modification } & \multicolumn{2}{|l|}{ MOM } & \multicolumn{2}{|l|}{ FOR } \\
\hline & & $\mathbf{R}_{\mathbf{t}}$ & Peak Area & $\mathbf{R}_{\mathbf{t}}$ & Peak Area \\
\hline 1 & Organic phase & 5.134 & 3175.67 & 8.734 & 268.57 \\
\hline 2 & $(85 \pm 2 \% \mathrm{v} / \mathrm{v})$ & 5.148 & 3276.76 & 8.698 & 276.54 \\
\hline 3 & & 5.248 & 3198.66 & 8.675 & 274.59 \\
\hline \multicolumn{2}{|c|}{$\% \operatorname{RSD}^{*}(<2)$} & 1.201 & 1.647 & 0.342 & 1.521 \\
\hline 1 & Effect of pH & 5.154 & 3178.08 & 8.615 & 269.05 \\
\hline 2 & (3.5 \pm 0.2 unit) & 5.175 & 3167.65 & 8.654 & 272.34 \\
\hline 3 & & 5.168 & 3267.49 & 8.706 & 263.52 \\
\hline \multicolumn{2}{|c|}{$\% \operatorname{RSD}^{*}(<2)$} & 0.207 & 1.713 & 0.527 & 1.695 \\
\hline 1 & Effect of flow rate & 5.234 & 3215.13 & 8.745 & 267.75 \\
\hline 2 & $(1 \pm 0.1 \mathrm{ml} / \mathrm{min})$ & 5.167 & 3156.36 & 8.665 & 270.59 \\
\hline 3 & & 5.106 & 3193.23 & 8.608 & 264.41 \\
\hline$\%$ RSD & & 1.239 & 0.931 & 0.794 & 1.156 \\
\hline
\end{tabular}

$*(\mathrm{n}=3), \%$ RSD (Percentage relative standard deviation) 
Table 4: Result of system suitability studies of the proposed method

\begin{tabular}{llll}
\hline Parameters & Values & & Acceptance criteria \\
\cline { 2 - 4 } & MOM & FOR & \%RSD $\leq 2$ \\
Peak area (\% RSD)* & 0.592 & 0.827 & $\%$ RSD $\leq 2$ \\
Retention Time (\%RSD)* & 0.277 & 0.441 & $\mathrm{~N}>2000$ \\
No. of theoretical Plates (N) & 9806.980 & 7447.98 & $\mathrm{~T} \leq 2$ \\
Tailing Factor (T)* & $1.182 \pm 0.112$ & $1.378 \pm 0.144$ & $\mathrm{R}_{\mathrm{s}}>2$ \\
Resolution (Rs)* & - & $11.865 \pm 0.396$ & \\
\hline
\end{tabular}

$*(n=6)$ number of determinations

Table 5: Results of formulation analysis using the proposed RP-HPLC method

\begin{tabular}{llll}
\hline Drugs & Labelled amount $(\boldsymbol{\mu g} /$ rotacap) & Amount found $(\boldsymbol{\mu g} /$ rotacap) & Amount found (\%)* \\
\hline MOM & 200 & $200.501 \pm 1.578$ & $100.250 \pm 0.789$ \\
FOR & 6 & $5.978 \pm 0.737$ & 0.787 \\
\hline
\end{tabular}

${ }^{*}$ mean \pm SD $(\mathrm{n}=6), \mathrm{SD}$ (Standard deviation), ** \% RSD (Percentage relative standard deviation)

\section{DISCUSSION}

In the growing era of international competition for maintaining the standard of products in high commercial and market value, development and validation of analytical method became obligatory. Analytical method development is the process of demonstrating whether an analytical method is acceptable for use in workplace to quantify the concentration of subsequent sample. The method development and validation should be performed as per the protocols and acceptance criteria set out in the ICH guideline Q2 (R1) and used within GMP and GLP environments. In proposed HPLC method, chromatographic separation was achieved on reversed phase mode consisting of a mixture of methanol-water ( $\mathrm{pH}$ adjusted to 3.5 with $0.05 \%$ ortho phosphoric acid) in the ratio of $85: 15 \% \mathrm{v} / \mathrm{v}$ on thermo $\mathrm{C}_{18}$ column at a flow rate of $1 \mathrm{ml} / \mathrm{min}$. The run time for the simultaneous estimation of drugs for the proposed method was $10 \mathrm{~min}$ as drugs eluted at $5.217 \mathrm{~min}$ (MOM) and $8.650 \mathrm{~min}$ (FOR). The tailing factor for both the peaks was found to be $<1.5$. The ability of the method to separate and accurately measure the peak of interests which indicate the specificity of the method. This method showed good linearity over the range of $33-300 \mu \mathrm{g} / \mathrm{ml}$ for MOM and 1-9 $\mu \mathrm{g} / \mathrm{ml}$ for FOR. The correlation coefficient was found to be greater than 0.998 which was within the limits specified (NLT 0.99). This gives confidence that the response and concentration are directly proportional. Moreover, the developed method (linearity range of $33-300 \mu \mathrm{g} / \mathrm{ml}$ for MOM and $1-9 \mu \mathrm{g} / \mathrm{ml}$ for FOR) was more sensitive than the reported method (linearity range FOR 13-193 $\mu \mathrm{g} / \mathrm{ml}$ and MOM 0.403-6.127 mg/ml). Precision had shown good results which prove that the method can be used for regular analysis. The standard addition and recovery studies were conducted to demonstrate the accuracy of the method. The recovery was found to be in the range of 98-102\%. So, the method can be used for the estimation of MOM and FOR from its dosage form, without any interference. In all deliberately varied conditions, the SD of retention time and peak area of both drugs were found to be within the acceptable limit. By using the above method, assay of the marketed formulation was carried out. The mean percentage recovery of the formulation was $99.60 \%$. Present assay, the amount of both the drugs recovered was found to be $100.250 \pm 0.789$ for MOM and $99.596 \pm 1.005$ for FOR. Moreover, in comparison with the method described in the literature the proposed method was found to be simple, sensitive and precise. The developed HPLC method was cost effective for routine quality analysis as the mobile phase utilizes water and methanol. Hence, the developed RP-HPLC assay method, was found to be appropriate for the analysis of drug in their pharmaceutical dosage form.

\section{CONCULSION}

The proposed RP-HPLC method was found to be simple, sensitive, precise and cost-effective for simultaneous determination of MOM and FOR in rotacaps on account of the low LOD, LOQ and \% RSD values $(<2)$. The proposed work contributed advantage in case of
HPLC method which was found to be economical because it does not require acetonitrile and ion pairing reagent. So, the developed method can be used for routine analysis in quality control department for analysing MOM and FOR in rotacaps.

\section{ACKNOWLEDGEMENT}

Authors are thankful to the Department of Pharmacy, Sumandeep Vidyapeeth Deemed University, Piparia, Vadodara, Gujarat, India for providing all the facilities throughout the work.

\section{AUTHORS CONTRIBUTIONS}

The complete research work was guided by Dr. A K Seth. Method development and validation works were carried out by Aarti. S. Zanwar. Further, the manuscript was drafted by Aarti. S. Zanwar and it was edited by Dr. Dhanya B. Sen and Dr. Ashim Kumar Sen. Authors read and approved the final manuscript.

\section{CONFLICT OF INTERESTS}

Declared none

\section{REFERENCES}

1. Allen DB, Bielory L, Derendorf H, Dluhy R, Colice GL, Szefler SJ. Inhaled corticosteroids: past lessons and future issues. J Allergy Clin Immunol 2003;112:S1-40.

2. Kosoglou T, Hubbel J, Xuan F, Cutler DL, Meehan AG, Kantesaria $\mathrm{B}$, et al. Comparison of the systemic bioavailability of mometasone furoate after oral inhalation from a mometasone furoate/formoterol fumarate metered-dose inhaler versus a mometasone furoate dry-powder inhaler in patients with chronic obstructive pulmonary disease. Int J Chronic Obstruct Pulm Dis 2013;8:107-16.

3. Nayak AS, Banov M, Corren J, Feinstein BK, Anthony Floreani, Friedman BF, et al. Once-daily mometasone furoate dry powder inhaler in the treatment of patients with persistent asthma. Ann Allergy Asthma Immunol 2000;84:417-24.

4. Akapo SO, Muhammad A. Validation of a RP-HPLC method for the assay of formoterol and its related substances in formoterol fumarate dehydrate. J Pharm Biomed Anal 2003;33:935-45.

5. Malik K, Kumar D, Tomar V, Kaskhedikar S, Soni L. A simple RPHPLC method for the simultaneous quantitation of chlorocresol, mometasone furoate and fusidic acid in creams. Pharm Sinica 2011;2:77-84.

6. Shaikh KA, Patil AT. Stability-Indicating HPLC method for the determination of mometasone furoate, oxymetazoline, phenyl ethanol and benzalkonium chloride in nasal spray solution. J Trace Anal Food Drugs 2013;1:14-21.

7. Kulkarni A, Nanda RK, Ranjane MN, Ranjane PN. Simultaneous estimation of nadifloxacin and mometasone furoate in topical cream by HPTLC method. Der Pharma Chem 2010;2:25-30.

8. Sharma N, Rao SS, Vaghela B. Validated stability-indicating high-performance liquid chromatographic method for 
estimation of degradation behaviour of eberconazole nitrate and mometasone furoate in cream formulation. Indian J Pharm Sci 2013;75:76-82.

9. El-Bagary RI, Elkady EF, Tammam MH, Elmaaty AA. Simultaneous determination of miconazole and hydrocortisone or mometasone using reversed phase liquid chromatography. Eur J Chem 2012;3:421-5.

10. Roy C, Chakrabarty J. Stability-Indicating validated novel RPHPLC method for simultaneous estimation of methylparaben, ketoconazole and mometasone furoate in topical pharmaceutical dosage formulation. ISRN Analytical Chemistry 2013;9. http://dx.doi.org/10.1155/2013/342794.

11. El-Bagary RI, Fouada MA, El-Shaalb MA, Tolba EH. Derivative, derivative of the ratio spectrophotometric and stabilityindicating RP-HPLC methods for the determination of mometasone furoate and miconazole nitrate in cream. J Chem Pharm Res 2013;5:368-78.

12. Vanani DR, Desai SD, Patel KG, Shah PA. Application of ratio derivative spectrophotometry for simultaneous determination of mometasone furoate and salicylic acid in semisolid dosage form. Int J Anal Bioanal Chem 2013;3:67-71.

13. Campestrini J, Lecaillon JB, Godbillon J. Automated and sensitive method for the determination of formoterol in human plasma by high-performance liquid chromatography and electrochemical detection. J Chromatogr B 1997;704:221-9.

14. Pai N, Patil SS. Development and validation of RP-HPLC method for estimation of formoterol fumarate and budesonide in pressurised meter dose inhaler form. Pharm Sinica 2013;4:15-25

15. Shah BD, Kumar S, Yadav YC, Seth AK, Ghelani TK, Deshmukh GJ. Analytical method development and method validation of tiotropium bromide and formoterol fumarate metered dose inhaler (Mdi) By using RP-HPLC method. Asian J Biochem Pharma Res 2011;1:145-55.

16. Gurjar NM, Seth AK, Zanwar A, Patel J, Deshmukh G. Development of first derivative spectroscopy method for estimation of budesonide and formoterol in combined dosage form. Pharma Sci Monitor 2012;3:82-92.

17. Zanwar AS, Sen DB, Ruhikar DB, Seth AK. Spectroscopic methods for the simultaneous estimation of mometasone furoate and formoterol fumarate in rotacaps. Indo Am J Pharm Res 2014;4:5928-32.

18. Katari S, Gorule V, Venkata R, Venkata KA. Validated method development for estimation of formoterol fumarate and mometasone furoate in metered dose inhalation form by high performance liquid chromatography. J Anal Bioanal Tech 2012;3:153-7.

19. Gujarati PZ, Thula KC, Maheshwari DG. Stability indicating HPLC method for simultaneous estimation of mometasone furoate and formoterol fumarate in combined dosage form. Pharmacophore 2014;5:219-30.

20. International Conference on Harmonization of Technical Requirements for Registration of Pharmaceuticals for Human use. Validation of Analytical Procedures: Text and Methodology ICH Q2(R1); 2005. 